\title{
Long-term, quantitative analysis of gametogenesis in autotriploid rainbow trout, Oncorhynchus mykiss
}

\author{
L. A. P. Carrasco ${ }^{1}$, S. Doroshov ${ }^{2}$, D. J. Penman ${ }^{1}$ and N. Bromage ${ }^{1}$ \\ 'Institute of Aquaculture, University of Stirling, Stirling, FK9 $4 L A, U K$; and ${ }^{2}$ Animal Science Department, \\ University of California, Davis, CA 95616, USA
}

\begin{abstract}
A long-term, quantitative analysis was conducted on the gametogenesis of autotriploid rainbow trout (Oncorhynchus mykiss) to quantify their degree of germline development and reproductive potential. Triploid and diploid (control) trout siblings were raised separately under identical conditions and sampled randomly for histological analysis. Triploid males underwent testicular development and proliferation of germ cells by mitosis and meiosis, progressing through initial phases of spermatogenesis at a similar pace to diploid controls. The effects of triploidy on males were most evident during the final stages of spermatogenesis, when all diploid males contained free spermatozoa in the lumen of most tubules (average relative frequency, $A R F=68.5 \%$ ), whereas triploid males contained predominantly spermatocytes $(\mathrm{ARF}=36.3 \%$ ) and morphologically abnormal spermatozoa ( $\mathrm{ARF}=31.8 \%$ ). In contrast, the gonadal development of triploid females was affected during its early stages; the major patterns observed were the arrest of the oogonia within oogonial clusters $(\mathrm{ARF}=30.4-71.1 \%)$, the appearance of small numbers $(\mathrm{ARF}=1.5-6.0 \%)$ of previtellogenic and early vitellogenic follicles, and the proliferation of non-follicular elements (vascular lacunae, fibrosis and tubular adenomas). In agreement with previous reports on the ovarian development of chromosomally female (3A:ZZW) triploid chickens, male-differentiating areas (ARF $=0.2-12.2 \%$ ) were observed in most triploid females examined, which by the end of the sampling period appeared as gonadal hermaphrodites. It is hypothesized that the lack of proper somatic-to-germ cell interactions prevents the segregation of the oocytes from the gonial clusters and may explain the early blockage observed during the gonadal morphogenesis of autotriploid female rainbow trout.
\end{abstract}

\section{Introduction}

Ploidy manipulation in fish has become an important commercial tool in recent years, and is centred on the production of triploid individuals (Ihssen et al., 1990, 1991; Galbreath and Thorgaard, 1995; Hussain, 1996). The main goal of producing triploid fish is to cause sterility, which is assumed to arise from the triploid genome of germ cells leading to aberrant disjunction at anaphase I and resulting in the suppression of gametogenesis (Thorgaard, 1986).

The production of sterile fish is of interest to the fish farming industry as a means of preventing the undesirable effects concomitant with sexual maturation in many teleosts, particularly salmonids. The reduction in growth resulting from a massive energetic investment in gonadal development (up to $10 \%$ of body weight in males and up to $30 \%$ of body weight in females), the deterioration of flesh quality during maturation and the high mortality at the time of spawning are among the deleterious effects that sexual maturation brings about in farmed stocks. Sterility also facilitates the release of exotic species into new ecosystems, prevents the loss of biodiversity

Received 10 July 1997. caused by escaped fish in areas of intensive farming, and is regarded as an important safety precaution for the testing of genetically manipulated (that is, transgenic) fish (Thorgaard, 1991; Devlin et al., 1994; Johnstone, 1995).

In spite of the growing commercial use of triploids, their reproductive development remains poorly understood. Evidence to date indicates that the reproductive effects of induced triploidy vary in different fish species and between the sexes, from complete or partial sterility to functional reproduction. In rainbow trout, as in other salmonids, there seems to be a marked difference in the effects of triploidy on the gonadal development of males and females. Triploid males show an endocrine profile similar to that of diploid males, and their germ cells enter meiosis with no obvious delay in comparison with diploid males, although subsequent spermatogenesis appears to be substantially delayed (Kobayashi et al., 1993), resulting in the production of small amounts of morphologically abnormal, aneuploid spermatozoa (Benfey et al., 1986).

In contrast, steroid hormone concentrations remain low in triploid females of up to 27 months of age (Nakamura et al., 1987). The ovaries of triploid females retain a string-like appearance (Cerisola and Dazarola, 1996), although small 
numbers of vitellogenic oocytes have been observed in triploid rainbow trout (R. F. Lincoln, unpublished, cited in Lincoln and Scott, 1984; Okada, 1985) and other triploid salmonids (Johnson et al., 1986; Benfey, 1995).

The majority of previous reports on the reproductive characteristics of triploid rainbow trout have focused on the gonadal histomorphology and steroid profiles at the time of first sexual maturation, rather than on providing a detailed account of gametogenesis throughout development. The present long-term, quantitative study aimed to: (i) obtain an accurate description of sexual differentiation and gametogenesis, (ii) quantify the degree of germline development and reproductive potential, and (iii) investigate possible histopathological aberrations arising during the gonadal development of male and female triploid rainbow trout.

\section{Materials and Methods}

\section{Animals}

Triploid rainbow trout were produced from broodstock selected from crosses of RTJ ('Javier') and RTD ('Davis') Mt Lassen-derived strains (2 years old, $1.2-1.5 \mathrm{~kg}$ body weight). Pooled eggs stripped from three mature females were fertilized with spermatozoa collected from two different males (water temperature $=13.6^{\circ} \mathrm{C}$ ). Triploidy was induced by a $27^{\circ} \mathrm{C}$ heat shock of $13 \mathrm{~min}$ duration applied to eggs $11 \mathrm{~min}$ after fertilization to induce the retention of the second polar body. Eggs were then incubated at $13 \pm 2^{\circ} \mathrm{C}$ for 26 days, when hatching took place. Ploidy was determined by measuring the nuclear size of erythrocytes with a Coulter counter and channelizer (Coulter Instruments, Hialeah, FL) (Wattendorf, 1986). Triploid and diploid (control) siblings were raised in separate tanks at similar density, feeding and water quality regimens $\left(10-18^{\circ} \mathrm{C}\right.$, ambient photoperiod).

\section{Experimental design}

Triploid and diploid groups were sampled at 7, 15, 20, 25 and 44 months after fertilization by administering an overdose of anaesthetic to randomly selected individuals in $0.01 \%(\mathrm{w} / \mathrm{v})$ benzocaine. After ploidy reassessment by Coulter counter, a separate fragment was collected for the anterior, median and posterior parts of the gonads when size made it possible, and fixed in $10 \%$ buffered formalin. Replicate sections (thickness $=5 \mu \mathrm{m}$ ) were prepared from a total of 346 paraffin wax-embedded tissue blocks, and stained with haematoxylineosin, the periodic acid-Schiff reaction, Heidenhain's iron haematoxylin and Masson's trichrome (Carleton, 1980). Slides were examined under low power magnification $(\times 10)$ with an Olympus BH-2 microscope linked to a Sony colour monitor via a Panasonic F10 videocamera. Three different fields were examined per section to ensure random sampling. A 'short line' Weibel's multipurpose grid (Graticules Ltd, Tonbridge, Kent) was placed in an eyepiece between the microscope and the videocamera, the image of the grid overlaying the gonadal section, and viewed on the monitor. Images of gonadal sections with the superimposed graticule segments were stored in a computer and analysed enlarged $\times 10-40$ their original mag-
Table 1. Sampling size and observed gonadal sex in diploid and triploid groups of rainbow trout, Oncorhynchus mykiss, at different ages

\begin{tabular}{|c|c|c|c|c|}
\hline \multirow{2}{*}{$\begin{array}{l}\text { Age } \\
\text { (months) }\end{array}$} & \multicolumn{2}{|c|}{ Males } & \multicolumn{2}{|c|}{ Females } \\
\hline & Diploid & Triploid & Diploid & Triploid \\
\hline 7 & II. & 9 & 11 & 11 \\
\hline 15 & 13 & 11 & 8 & 9 \\
\hline 20 & 4 & 4 & 6 & 6 \\
\hline 25 & 9 & 10 & 10 & 10 \\
\hline 44 & 1 & 1 & 5 & 10 \\
\hline Totals & 38 & 35 & 40 & 46 \\
\hline
\end{tabular}

nification for the clarification of cellular details using the Image Pro-Plus ${ }^{12,}$ image-analysis software (Media Cybernetics, Silver Spring, MD). A constant number of 32 graticule end points were considered per field ( 96 per section), the number of grid points laying within a given cell stage or category were recorded, and relative frequencies ( $R F s$ ) for a given cell category computed as:

Relative frequence

$$
=\frac{\text { Grid points laying within cell category }}{\text { Total number of grid points }} \times 100
$$

Gonadal cell stages were classified according to previous morphological studies on gametogenesis in rainbow trout (Billard, 1986, 1992; Bromage and Cumaranatunga, 1988). With the exception of the first sampling, sex was easily ascertained for all sections according to the general morphology and staining affinity of the gonad. The main morphological feature to establish sex at 7 months of age was the appearance of the characteristic lamellar structure present in female teleosts since, in the majority of the individuals sampled at this time, the lobular arrangement typical of males was still not established. Thus, individuals with gonads displaying the lamellar structure at this age were classified as females, and the remaining individuals were assumed to be males. A summary with the number and sex of individuals analysed at every sampling time for both ploidy groups is presented (Table 1).

\section{Statistical analysis}

Relative frequencies were averaged for each fish to obtain the individual relative frequency (IRF). Individual relative frequencies were averaged for each ploidy group to calculate the average relative frequency (ARFs) at every sampling time. Average relative frequencies were arc-sine transformed and compared among ploidy groups by one-way ANOVA (Sokal and Rohlf, 1981). Differences were considered significant at $P<0.05$.

\section{Results}

\section{Males}

Gonadal structure at 7 months after fertilization. In 10 of the 11 diploid males sampled at 7 months of age, the gonad 

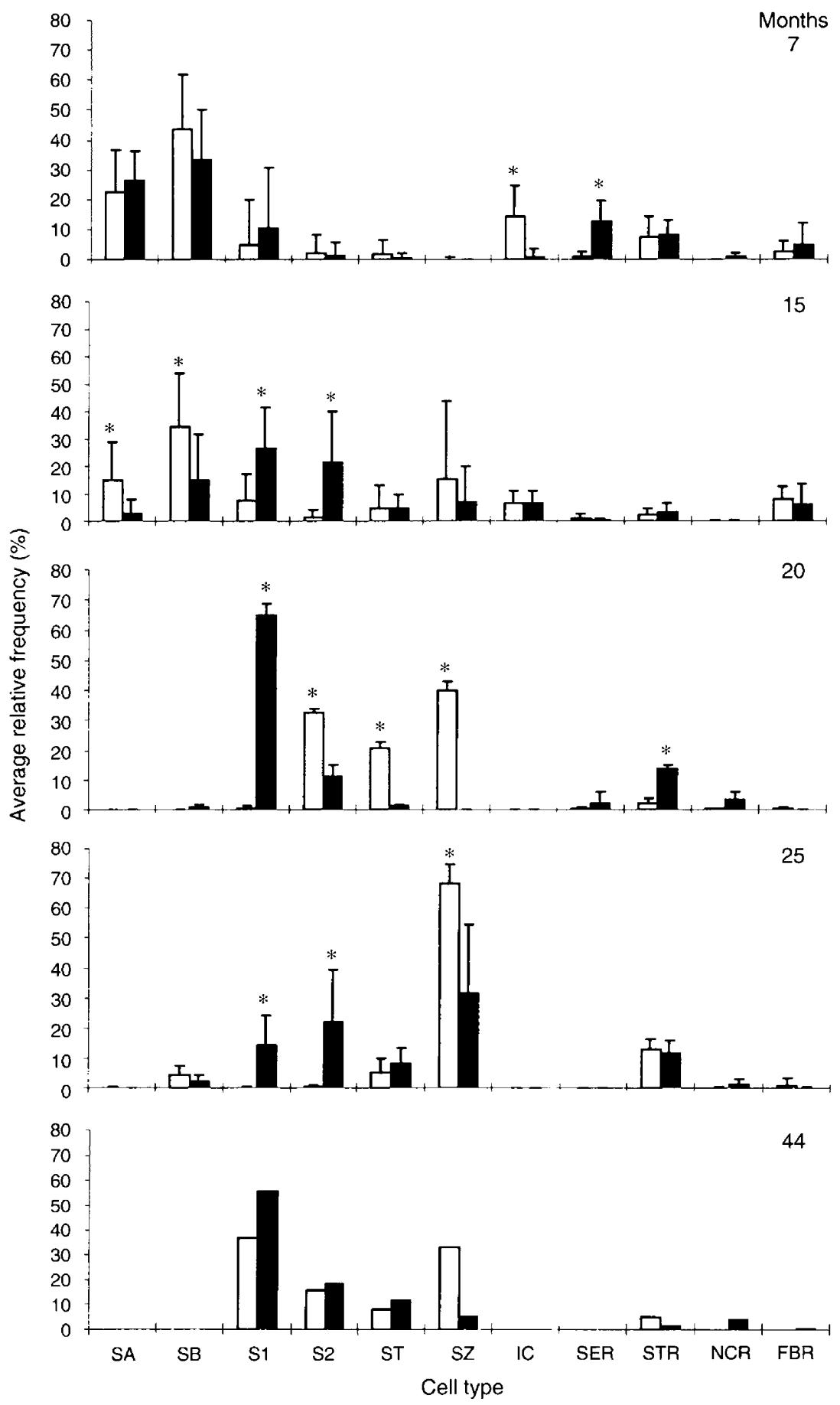

Fig. 1. Average relative frequencies of gametogenic cells and non-parenchymal components in diploid $(\square)$ and triploid ( $\square$ ) rainbow trout testes at different age stages. Bars represent standard deviations, asterisks denote significantly different means $(P<0.05)$. SA, type A spermatogonia; SB, type B spermatogonia; S1, primary spermatocytes; S2, secondary spermatocytes; ST, spermatids; SZ, spermatozoa; IC, interstitial cells; SER, Sertoli cells; STR, stroma; NCR, necrosis; FBR, fibres.

consisted of groups of 5-6 cells at the spermatogonia A and B stages that appeared cysted in circular arrangement and externally delimited by a thin layer of connective stroma. Typically, spermatogonia type $B(A R F=43.5 \%$; Fig. 1$)$ were found in a central position within the cysts and showing mitotic activity, while type A spermatogonia $(A R F=22.4 \%)$ were located peripherally. These cysts were surrounded by variable numbers of interstitial (Leydig) cells (ARF $=14.2 \%$ ) characterized morphologically by flat, scarce cytoplasms and darkly staining spheroidal nuclei, located in close contact with the external wall 
of the cysts. In the margins of the gonad, the cystic arrangement was not present, but instead spermatogonia (generally of type A) were in close juxtaposition with interstitial cells, eosinophilic fibres and myeloid-resembling cells (Fig. 2a). One precocious diploid male displayed a more advanced gonadal morphology characterized by the establishment of the lobular arrangement in which primary spermatocytes (IRF $=53.1 \%$ ) were embedded in Sertoli cells (IRF $=1.1 \%$ ) delimited by thin trabeculae of connective stroma. A few scattered lobules showed signs of meiotic activity with secondary spermatocytes $(\mathrm{IRF}=22 \%)$ and spermatids $(\mathrm{IRF}=16.7 \%$ ) being located in the central area of the lobules.

Most males in the triploid group presented a similar anatomy of the gonad, although showing less abundant spermatogonial cysts, more prominent Sertoli cells and a significantly smaller number of interstitial cells than in diploid males (ARF $=0.9 \%$; Figs 1 and $2 \mathrm{~b}$ ). In the margins of the gonad, uncysted spermatogonia were found in close contact with scarce interstitial cells and eosinophilic fibres. Four out of the nine triploid males sampled showed signs of progress through spermatogenesis. These exhibited the nested arrangement of the spermatogonia observed in diploid males, with primary spermatocytes $(A R F=10.5 \%)$ in the centre of some cysts. In one precocious triploid male, the lobular arrangement was evident, with spermatogonia type $B$ in the periphery of the lobules and primary and secondary spermatocytes positioned more centrally. Some spermatids (IRF $=5.2 \%$ ) with irregular, uneven profiles were present in the lumen of a few lobules.

Gonadal structure at 15 months after fertilization. The testes of ten diploid males at 15 months of age were organized in the lobular arrangement characteristic of salmonid males (Fig. 2c). The lobules appeared filled with spermatogonia type $B$ $(\mathrm{ARF}=34.5 \%)$ and a few primary spermatocytes $(\mathrm{ARF}=7.5 \%)$ embedded in Sertoli cells and loosely positioned around a central lumen. Thin trabeculae of connective stroma delimited the lobules. Interstitial cells, eosinophilic fibres and blood vessels with erythrocytes and myeloid-resembling cells were located in the margins of the gonad. Three diploid males contained morphologically normal spermatozoa in the centre of most lobules and spermatids at the periphery (IRFs $=63-73 \%$ and $4-8 \%$, respectively). In these three fish, spermatogonia and interstitial cells were visible within the trabeculae, which appeared thicker than it did in the previous males. Fibres and erythrocytes were also visible within the trabeculae. Free spermatozoa were present in the lumen of their spermatic ducts. The ducts were lined by a single layer of ciliated epithelium, with large blood vessels running through the duct wall.

The testes of triploid males were also organized in lobules, but contained significantly fewer spermatogonia and showed further development in spermatogenesis than diploid males (Figs 1 and 2d). All 11 individuals sampled had entered meiosis, with the bulk of most lobules being filled with significantly more primary $(A R F=26.5 \%$ ) and secondary spermatocytes $(21.3 \%)$ than in diploid males at this age (Fig. 2e). Spermatocytes had irregular shapes and, in many cases, their cytoplasms appeared vacuolated. When present, spermatids $(\mathrm{ARF}=4.6 \%$ ) were located in the central lumen of the lobules, displaying significant heterogeneity in size and shape, and frequently concomitant with cell debris. Intercellular spaces appeared filled by a basophilic substance reminiscent of colloid. The trabeculae delimiting the lobules appeared thicker than in diploid males and contained interstitial cells $(A R F=6.5 \%)$. The margins of the gonads contained some spermatogonia type $A$ $(\mathrm{ARF}=2.9 \%)$ associated with eosinophilic structures resembling collagen fibres. Five of the eleven triploid males examined had variable proportions of spermatozoa (IRFs $=0.7-41.3 \%$ ) present in the central lumen of most lobules. The size and shape of spermatozoa varied among the lobules, although in some cases they exhibited homogeneous morphology and visible flagella. In one of these males, most lobules were filled with normal-looking spermatozoa (IRF $=41.3 \%$ ) while some appeared empty after apparent spermiation, delimited by thickened trabeculae containing primary spermatocytes embedded in Sertoli cells. In this male, spermatozoa were present in the lumen of the spermatic duct which appeared to be lined by ciliated epithelium and was highly vascularized.

Gonadal structure at 20 months after fertilization. All four diploid males were completing spermiogenesis at the age of 20 months, and showed variable numbers of fully differentiated spermatozoa in the lumen of their lobules. Secondary spermatocytes $(\mathrm{ARF}=32.7 \%)$ and spermatids $(\mathrm{ARF}=20.8 \%)$ were observed in a marginal position within the lobules (Fig. $2 \mathrm{f}$ ). Free spermatozoa $(\mathrm{ARF}=39.8 \%$ ) presented regular, even morphology and homogeneous size across the lobules. An extracellular basophilic substance was also present in the lumen of these lobules.

In triploid males, the stromal component delimiting the testicular lobules appeared to be significantly more prominent than in diploid males at this age, and showed intense vascularization. Most cells within the lobules were at the stage of primary spermatocytes $(A R F=65.1 \%)$ with vacuolized cytoplasms, although some secondary spermatocytes $(\mathrm{ARF}=11.1 \%)$ and very few spermatids $(\mathrm{ARF}=1.1 \%)$ were also present. However, these appeared in significantly smaller numbers than in diploid males (Fig. 1). The central lumen of the lobules contained filamentous, thread-like structures and cell debris. No spermatozoa were present in the lumen of the spermatic duct (Fig. 2g).

Gonadal structure at 25 months after fertilization. All diploid males had spermiated at 25 months of age (Fig. 2h). The central area of many testicular lobules appeared as an empty space, while in the proliferating stroma, type $B$ spermatogonia $(\mathrm{ARF}=4.4 \%)$ and very few spermatocytes $(\mathrm{ARF}=0.4 \%)$ were observed among a relatively high proportion of fibres $(\mathrm{ARF}=0.9 \%)$. Lobules that still contained free spermatozoa in their lumen $(A R F=68.5 \%$ ) showed signs of degeneration such as cell agglutination and overstaining, and a basophilic substance filled the intercellular spaces. Some residual spermatozoa were visible in the spermatic duct of all ten males sampled.

In contrast, most triploid males were still completing spermiogenesis, and had significantly higher proportions of spermatocytes and fewer spermatozoa than did diploid males (Fig. 1). There seemed to be some overlap between the first and second gonadal cycle in the ten triploid males examined at this age. Typically, abnormal spermatozoa (ARF $=31.8 \%$ ), spermatids $(A R F=8.1 \%)$ and secondary spermatocytes $(A R F=22.1 \%)$ 
were found in the centre of the lobules together with cell debris and colloid. The lobules were delimited by proliferating stroma containing type $\mathrm{B}$ spermatogonia $(\mathrm{ARF}=2.3 \%)$ and primary spermatocytes $(A R F=14.2 \%)$. Spermatozoa and spermatids presented irregular morphology and variable cell size, and cytoplasmic vacuolization was evident in secondary spermatocytes. However, three of the ten triploid males exhibited uniform and morphologically normal free spermatozoa (IRFs $=48-69 \%$ ) in the lumen of most lobules (Fig. 2i). In two of these cases, normal-looking spermatozoa were also found in the lumen of the spermatic duct, which was lined by a single layer of ciliated epithelium (Fig. 2j).

Gonadal structure at 44 months after fertilization. In the only diploid male available for histological analysis at 44 months of age, the testis had completed a new cycle and progressed to the stage of spermiogenesis. Free spermatozoa $(\mathrm{IRF}=33.3 \%$ ) were visible in the lumen of most lobules, while spermatids were located peripherally. Meiotic activity was still evident in some lobules, where primary $(\mathrm{IRF}=36.4 \%$ ) and secondary spermatocytes (IRF $=15.6 \%$ ) appeared concomitantly with a few spermatids (IRF $=8.3 \%$ ). No spermatozoa were visible in the lumen of the spermatic duct. The duct wall presented a heavy fibrous infiltration alternating with areas of fat deposit.

The triploid male contained mostly primary spermatocytes (IRF $=56.1 \%)$ entering meiosis with some secondary spermatocytes $(\mathrm{RF}=18.2 \%)$ and spermatids $(11.8 \%)$ in the centre of the lobules. Some lobules also contained scattered spermatozoa (IRF $=4.8 \%$ ) of heterogeneous size and cell morphology, together with cell debris. Localized areas of fibrosis were also evident throughout the testis. No spermatozoa were visible in the lumen of the spermatic duct, which appeared heavily infiltrated with fibres and adipose tissue.

\section{Females}

Gonadal structure at 7 months after fertilization. In all eleven diploid females examined at 7 months of age, the ovary was organized in a series of transverse septa extending along the ovarian axis known as the ovigerous lamellae. The lamellae opened into a central ovarian lumen, with their external surface covered by a single layer of cubical epithelium (germinal epithelium), and the gonad was externally delimited by the peritoneum, continuous with the tunica albuginea. The tunica albuginea consisted of a thin fibrous layer covered externally with ciliated columnar epithelium. The lamellae appeared filled with stage 3 oocytes (ARF $=64.8 \%$; Fig. 3) embedded in a loosely bound connective stroma containing scattered oogonia $(\mathrm{ARF}=3.2 \%)$, stage $1(\mathrm{ARF}=1.2 \%)$ and stage $2(\mathrm{ARF}=10.6 \%)$ oocytes and thin blood capillaries. Stage 3 oocytes exhibited a basophilic cytoplasm and a central nucleus with several nucleoli lying close to the nuclear envelope. They were surrounded by a single layer of flattened granulosa cells and some squamous thecal cells. A few oocytes had developed cytoplasmic vesicles in the periphery of the ooplasm, thus entering stage 4 $($ ARF $=0.9 \%$.

All triploid females examined showed a much more rudimentary gonadal anatomy than their diploid counterparts, with non-follicular elements over-represented in their ovaries
(Fig. 4). Although the lamellar organization was present in all triploid females, the central lumen of the ovary appeared disrupted longitudinally as opposite lamellae were fused in bridges running the width of the organ, giving it a closed appearance (Fig. 5a). The tunica albuginea appeared greatly thickened by the presence of 5-6 layers of heterogeneous fibrous elements similar to collagen and smooth-muscle fibres intermixed with flattened cells with a central, ellipsoidal nucleus.

Germ cells within the lamellae were at the oogonial stage (ARF $=71.1 \%$; Fig. 3). They had a large spheroidal nucleus positioned centrally, often showing signs of vacuolization and pyknosis, and a stranded cytoplasm. In 5 of the 11 triploid females, the oogonia were cysted in groups of 4-8 cells surrounded by a thin fibrous layer. In the other six fish, the oogonia appeared uncysted with some fibres positioned between them $(A R F=9.3 \%)$. Mitotic figures were frequent among the oogonia in all females examined. A moderate proliferation of tubular structures very similar to renal tubules was interspersed between the oogonia in two of the triploid females studied (IRFs $=7.8$ and $12.6 \%$, respectively). Localized foci of necrosis $(\mathrm{ARF}=5.8 \%)$ and a moderate infiltration of eosinophilic inflammatory cells $(\mathrm{ARF}=1.9 \%)$ were evident under the germinal epithelium covering the outer surface of the lamellae.

Gonadal structure at 15 months after fertilization. Most of the oocytes in the ovaries of diploid females at 15 months of age had reached stage 4, clearly identified by the presence of yolk vesicles staining pale mauve in their cytoplasm $(A R F=41.7 \%$; Fig. 3). Radial striations of the zona radiata were visible between the granulosa and the oocyte membrane. The granulosa cells were cuboid, while thecal cells showed a flattened appearance. Large numbers of stage 3 oocytes were still evident $(A R F=32.7 \%)$, together with scattered oocytes at stage $2(\mathrm{ARF}=5.2 \%)$. A few atretic follicles $(\mathrm{ARF}=2.4 \%)$ were also present, recognizable by a hypertrophied granulosa penetrating the zona radiata and shrinking of the oocyte which had separated from the theca. The stroma around the follicles contained thin fibres and few erythrocytes ( $A R F=7.4 \%$ ).

Triploid females exhibited a closed lamellar ovarian architecture at this age. The gonad appeared delimited by a thick, fibrous tunica albuginea in which focal areas of cytolysis and necrosis were common $(\mathrm{ARF}=5.6 \%$ ). Fibres underneath the epithelium of the tunica infiltrated the underlying germinal tissue, which was replaced by adipose deposits in some areas. The columnar cells of the germinal epithelium were significantly enlarged ( $A R F=3.9 \%$; Fig. 4) and some cell debris seemed to be washing up into the ovarian lumen.

Within the lamellae, oogonia $(A R F=57.3 \%)$ appeared nested in groups of $4-20$ cells surrounded by a thin fibrous layer in all nine females examined (Fig. 5b). The oogonia had a stranded cytoplasm and nuclei of variable size with frequent signs of vacuolization and karyorhexis, and occasional mitotic figures were observed. These cysts were surrounded by abundant pink-staining fibrous elements $(\mathrm{ARF}=18.4 \%)$ with central, elongated nuclei, and moderate amounts of inflammatory cells (ARF $=1.4 \%$ ). Some dark-staining flattened cells with ellipsoidal nuclei reminiscent of thecal cells were also evident among the cysts. In addition, tubular structures resembling kidney 

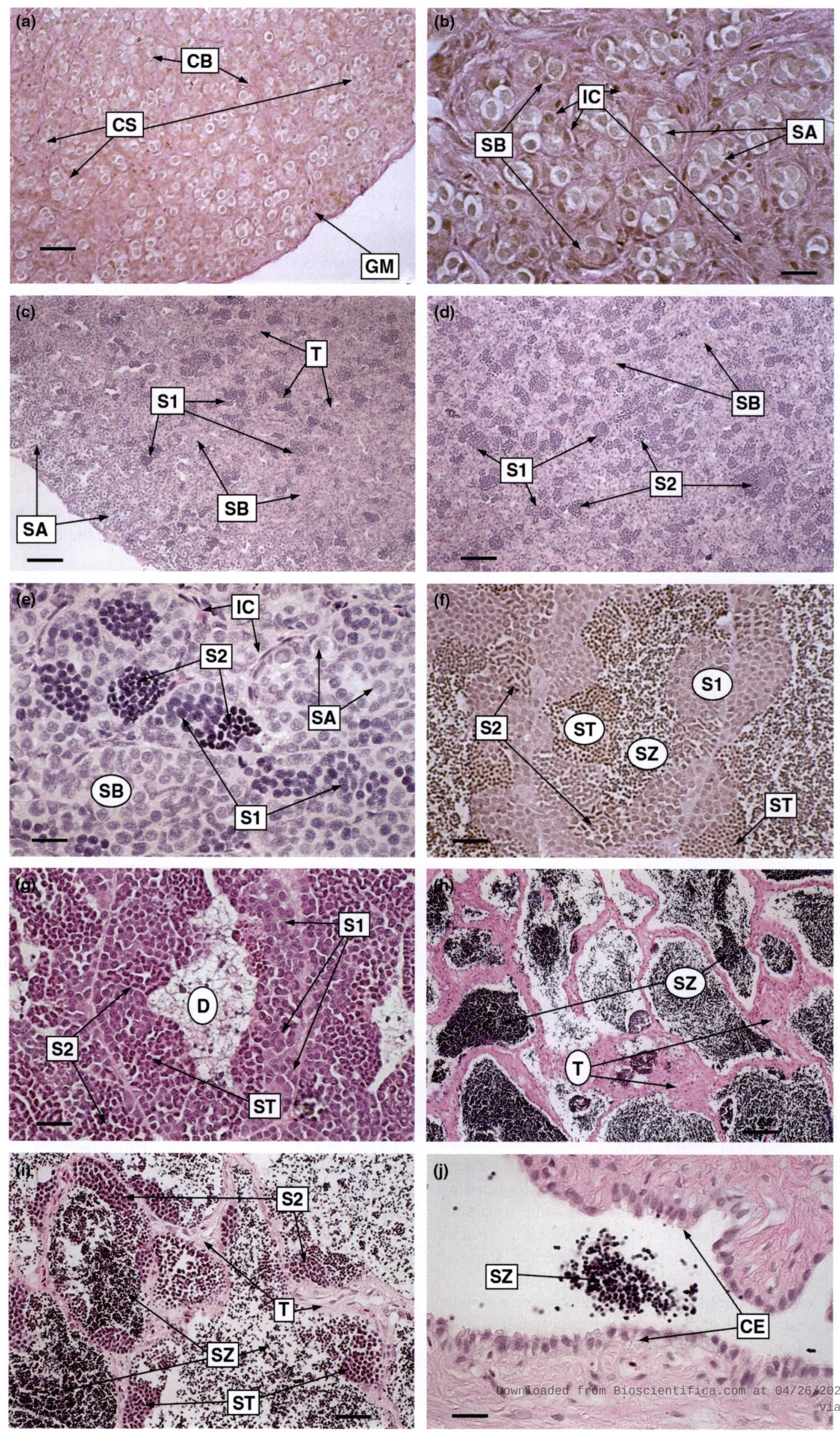
tubules and abortive glomerulae were interspersed among the gonial cysts in three of the females examined (IRFs $=2.3-$ $7.8 \%$ ). The ovaries of three of the triploid females examined seemed to be undergoing a significant change: isolated foci of dark-staining areas (IRF $=0.8-6.8 \%$ ) appeared to be developing among the gonial cysts, giving these zones a patchy appearance. Cells within these areas were much smaller than oogonia, and appeared morphologically similar to primary spermatocytes (hereafter referred to as 'spermatogenic cells'). These areas were not clearly delimited by an outer layer, but instead were located in close proximity to the gonial cysts.

Gonadal structure at 20 months after fertilization. All six diploid females examined were approaching ovulation at 20 months of age. The lamellar organization of the ovary appeared masked by the large size of the oocytes, which had completed growth to the late stage 6 of oogenesis $(\mathrm{ARF}=50.2 \%$; Fig. 3). These oocytes were characterized by the presence of many large yolk globules in their ooplasm, the yolk vesicles being restricted to the area immediately adjacent to the oocyte membrane (Fig. 5c). The nucleus or germinal vesicle of these oocytes presented a folded nuclear envelope and was slightly displaced from the centre. The zona radiata appeared thicker than in the previous sample, and the granulosa cells had also become more flattened. Some oocytes were still at stage 5 (ARF $=9.2 \%$ ), showing smaller yolk granules in the ooplasm adjacent to the oocyte membrane and a centrally positioned nucleus. A few atretic follicles were also evident in all females (ARF $=5.4 \%)$, characterized by a hypertrophied granulosa with an irregular basement membrane, and appeared filled with acidophilic fragments of the zona radiata and yolk granules. Small numbers of stage $3(\mathrm{ARF}=4.2 \%)$ and stage 4 ( $\mathrm{ARF}=0.7 \%$ ) oocytes were embedded in a well-vascularized stroma.

The ovaries of the triploid females sampled at this age retained the general morphology observed in the previous sample (Fig. 5d). The gonad presented a closed lamellar architecture with a heavy infiltration of fibres $(A R F=13.7 \%)$, fat deposits and scattered foci of necrosis (ARF $=3.2 \%$; Fig. 4). Large vascular lacunae expanding under the germinal epithelium were evident in three of the six fish examined. These appeared as distended irregular spaces delimited by a discontinuous endothelium and filled with myeloid-resembling cells (IRFs = $2.2-5.6 \%$ ) and some cell debris. Oogonia (ARF $=61.4 \%$; Fig. 3 ) appeared nested within the lamellae, surrounded by a fibrous connective layer and exhibiting frequent pyknosis and karyorhexis. The ovary of a single female presented a few normal follicles (IRF $=8.9 \%$ ) with oocytes at stage 4 and a normally developed granulosa surrounded by flattened thecal cells.

In two of the females sampled, the patchy configuration described previously was evident (Fig. 5e,f). Interspersed among the oogonia, spermatogenic cells showed dense chromatin staining and appeared similar in size and morphology with secondary spermatocytes (IRFs $=3.3 \%$ and $6.7 \%$, respectively). No tubular formations were found at this age in any of the triploid females examined.

Gonadal structure at 25 months after fertilization. All of the ten diploid females sampled at 25 months of age had ovulated. Large numbers of postovulatory follicles occupied most of the gonad ( $\mathrm{ARF}=34.6 \%$; Fig. 3). These appeared as collapsed structures with a proliferating granulosa filling the space previously occupied by the oocyte, and a theca that was continuous with the ciliated germinal epithelium. Variable numbers of atretic follicles (ARF $=9.2 \%$ ) were also found in all ovaries examined. Atretic oocytes were separated from a hypertrophied granulosa, with the striations of the zona radiata still visible. The globular organization of the yolk had been lost and, instead, a homogeneous mass of acidophilic material filled the entire ooplasm. Postovulatory follicles and atretic oocytes appeared embedded in a loosely bound stroma in which oocytes at stages 3,4 and 5 were developing.

Although the general organization noticed in the ovaries of triploid females during previous samples was conserved at 25 months of age, six of the ten females examined exhibited clear gonadal hermaphroditism at this age. Large areas of the ovary were occupied by small, dark-staining cells morphologically identical to spermatocytes and spermatids, with no clear delimiting membrane (IRF $=4.4-15.8 \%$ ). Spermatogenic cells within these areas appeared to be undergoing meiosis, with cells resembling spermatids located centrally and secondary spermatocytes located more peripherally. Macroscopically, the gonad appeared as a fibrotic organ retaining a closed lamellar architecture in which spermatogenic areas and nests of 15-30 vacuolized oogonia $(A R F=43.4 \%$ ) concurred with vascular lacunae $(A R F=1.5 \%)$, necrotic foci $(A R F=3.2 \%)$ and fat deposits. The lamellae appeared lined by a significantly enlarged germinal epithelium. In three of the ten females analysed, small numbers of stage 4 oocytes (IRFs $=1.1-10.2 \%$ ) appeared to be developing normally among the oogonial nests, frequently in close juxtaposition with spermatogenic areas. These oocytes contained cortical alveoli in their cytoplasms, and had a clearly differentiated zona radiata, granulosa and thecal layer (Fig. 5g). The tubular formations observed in previous samples had invaded large parts of the ovary in three cases $($ IRFs $=14.4-24.4 \%$; Fig. 5h). Cylindrical tubules contained a central lumen filled with an amorphous eosinophilic substance. The lumen was lined by a single layer of cuboid epithelium with spherical nuclei positioned centrally.

Gonadal structure at 44 months after fertilization. Diploid females were approaching a second ovulation and spawning at

Fig. 2. Gonadal photomicrograph from (a) a 7-month-old diploid rainbow trout male stained with the periodic acid-Schiff reaction and counterstained with Heidenhain's iron haematoxylin (PAS-HIH); (b) a 7-month-old triploid male stained with PAS-HIH; (c) a 15-month-old diploid male stained with haematoxylin-eosin (HE); (d,e) a 15-month-old triploid male stained with HE; (f) a 20-month-old diploid male stained with PAS-HIH; (g) a 20-month-old triploid male stained with HE; (h) a 25-month-old diploid male stained with HE; (i) a 25-month-old triploid male stained with HE; and (j) the spermatic duct of a 25 -month-old triploid male stained with $\mathrm{HE}$. CB, cyst boundary; $\mathrm{CE}$, ciliated epithelium; CS, cysted spermatogonia; D, cell debris; GM, gonadal margin; IC, interstitial cells; SA, spermatogonia type A; SB, spermatogonia type B; S1, primary spermatocytes; S2, secondary spermatocytes; ST, spermatids; SZ, spermatozoa; T, trabeculae. Scale bars represent (a, i) $50 \mu \mathrm{m}$; (b, e, f, g, j) $25 \mu \mathrm{m}$; (c, d, h) $100 \mu \mathrm{m}$ 

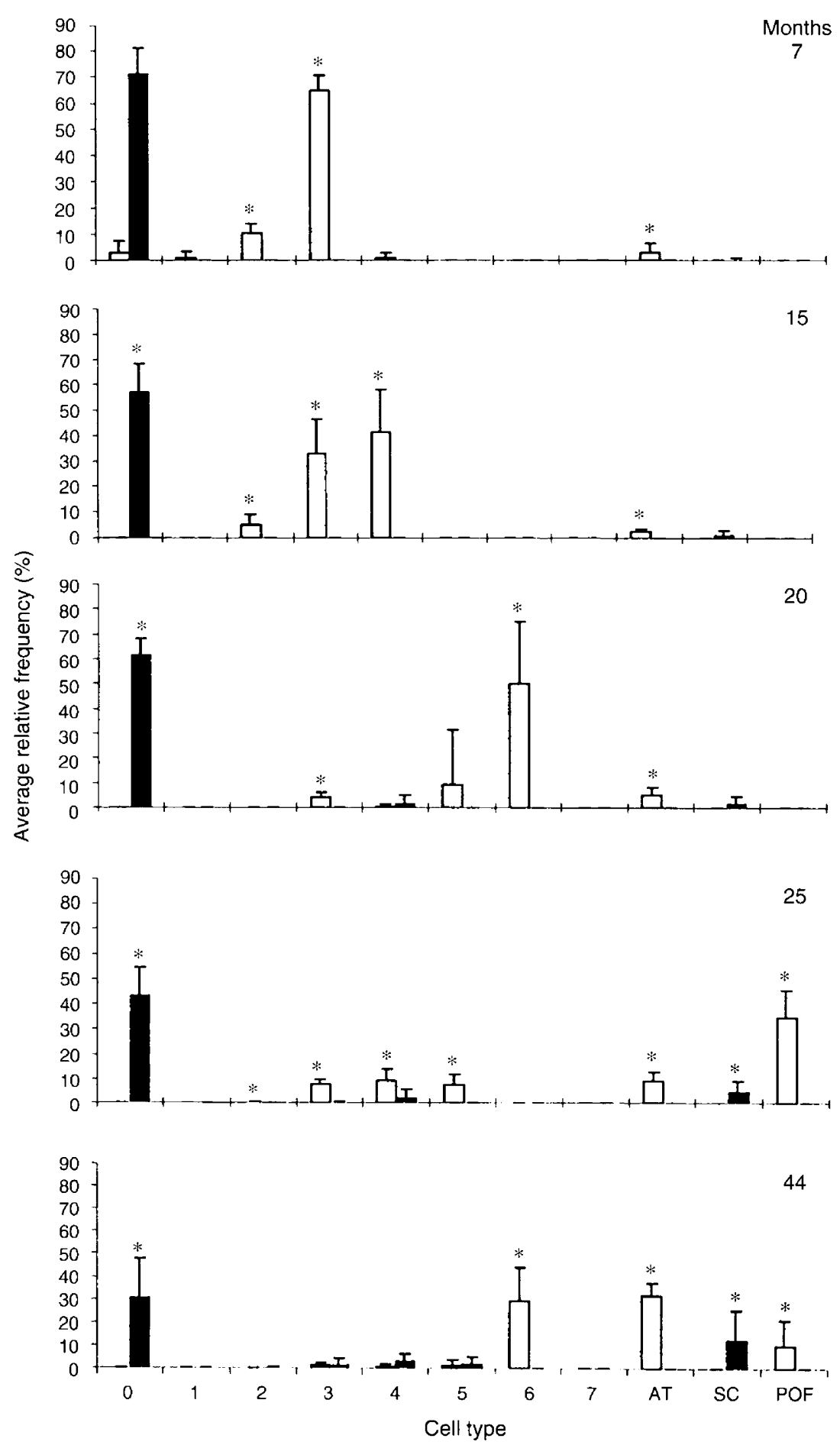

Fig. 3. Average relative frequencies of gametogenic cells in diploid ( $\square$ ) and triploid ( rainbow trout ovaries at different age stages. Bars represent standard deviations, asterisks denote significantly different means $(P<0.05$ ). 0 , oogonia; $1-7$, oocyte stages (after Bromage and Cumarantunga, 1988); AT, atretic oocytes; SC, spermatogenic cells; POF, postovulatory follicles.

44 months of age (Fig. 3). The composition of the ovary appeared basically identical to that observed in the sample taken 25 months after fertilization, with many oocytes at stage $6(\mathrm{ARF}=28.9 \%)$ and a new wave of stage $3-4$ oocytes developing within the stroma. Atretic follicles were numerous in all diploid females examined $(\mathrm{ARF}=31.4 \%)$.

The lamellar architecture had been replaced by a more lobular appearance reminiscent of the testicular anatomy in six 

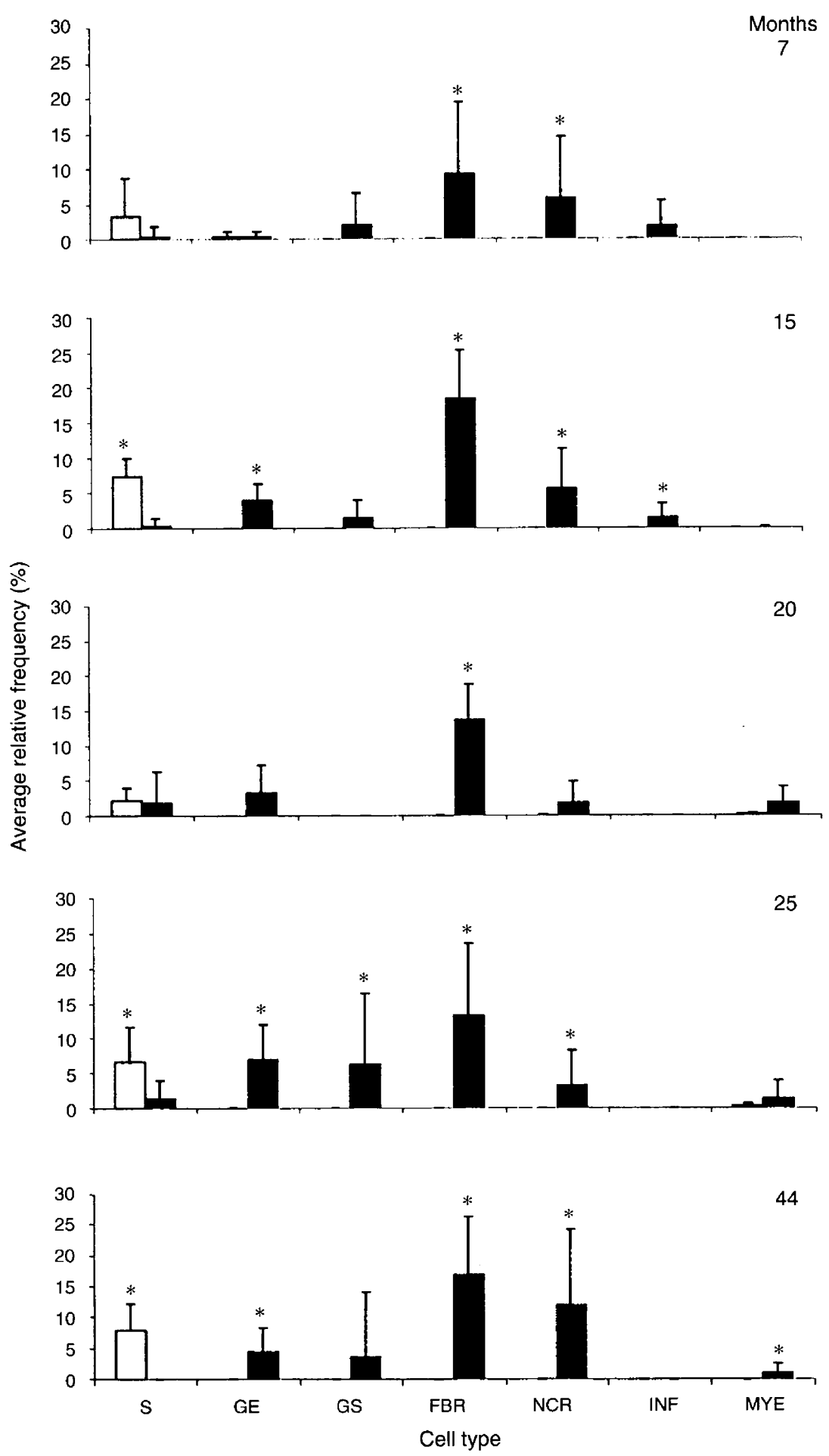

Fig. 4. Average relative frequencies of non-follicular components in diploid ( $\square$ ) and triploid $(\boldsymbol{\square})$ rainbow trout ovaries at different age stages. Bars represent standard deviations, asterisks denote significantly different means $(P<0.05)$. S, stroma; GE, germinal epithelium; GS, glandular structures; FBR, fibres; NCR, necrosis; INF, inflammatory cells; MYE, myeloid-resembling cells.

of the ten triploid females sampled at this age (Fig. 5i). Spermatogenic areas were now present in nine of the ten females examined $(A R F=12.2 \%)$, in most cases concomitant with oogonial nests $(\mathrm{ARF}=30.4 \%)$. Many of the male- differentiating areas appeared to be at late stages of spermiogenesis (Fig. 5j), with most cells resembling spermatids and, at least in one case, morphologically abnormal spermatozoa in the central areas of some cysts (IRF $=38.6 \%$ ). Pyknosis and 

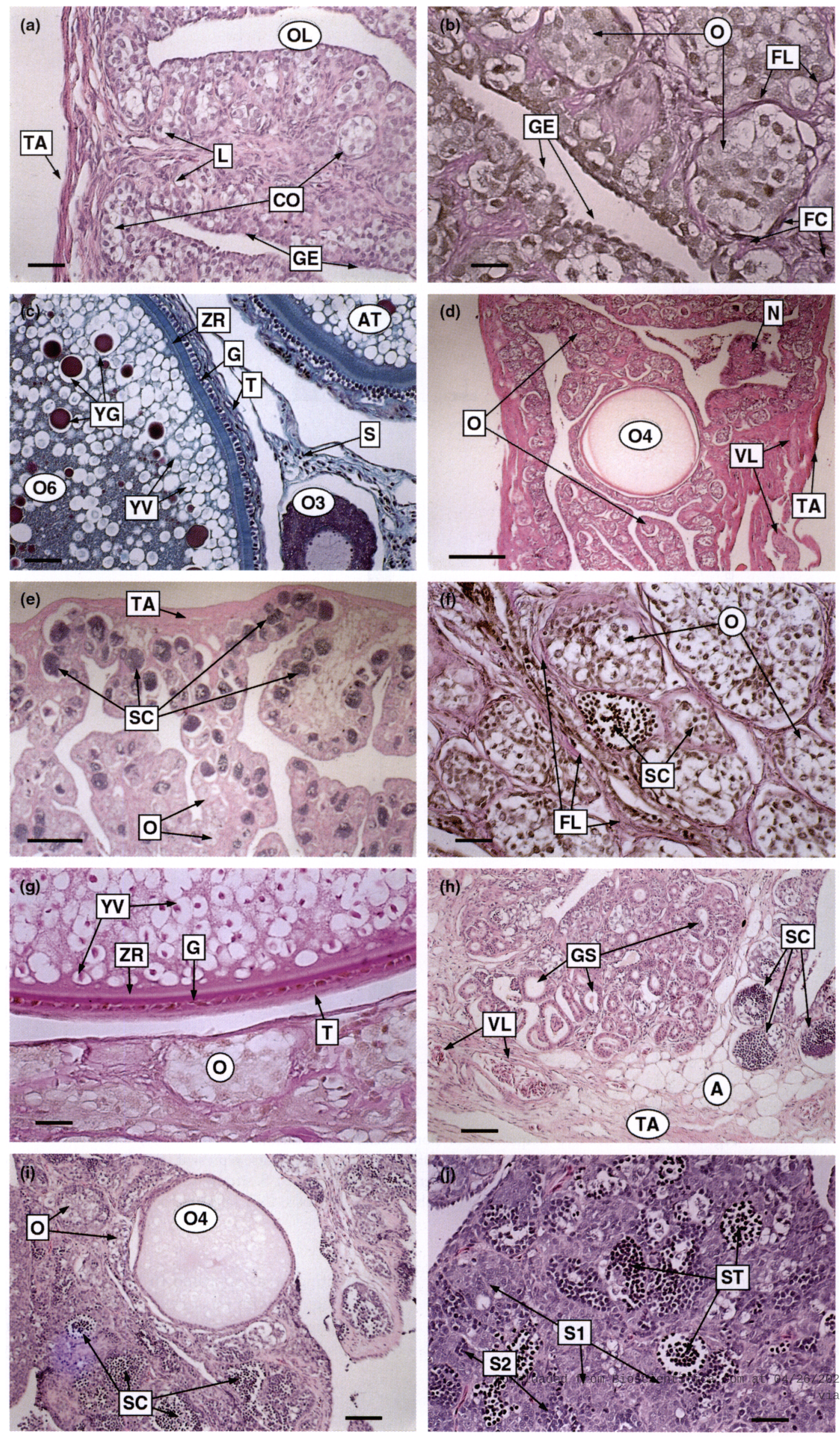
karyorhexis were frequent within the oogonial nests. A few normally developed follicles contained oocytes at stage 4 $(A R F=3.1 \%)$, and in three of the females these had entered stage 5 (IRFs $=3-9.5 \%$ ), showing small exogenous yolk granules in the periphery of the ooplasm. Fibres were abundant $(A R F=16.8 \%)$ throughout the gonads of all triploid females, in some cases forming localized dense agglomerations of neoplastic appearance. Cylindrical structures similar to kidney tubules were evident in two females (IRF $=3.3 \%$ and $33.3 \%$, respectively). Fat deposits, vascular lacunae and necrotic foci were observed in all triploid females examined (Fig. 4).

\section{Discussion}

In general, the patterns of testicular development observed in triploid males in this study are in accordance with previous findings (Lincoln and Scott, 1984; Nakamura et al., 1987; Kobayashi et al., 1993; Cerisola and Dazarola, 1996). Triploid males progressed through initial phases of spermatogenesis at similar or even faster rates than their diploid counterparts, and both ploidy groups contained precocious males that produced spermatozoa by the age of 15 months. Differences were more apparent at the completion of spermatogenesis (20-25 months of age), when all diploid males contained free spermatozoa in the lumen of most tubules, whereas triploid males contained predominantly spermatocytes and abnormal spermatids.

Thus, triploidy in male rainbow trout seems to affect spermiogenesis (transformation of spermatids into spermatozoa) and spermiation rather than the proliferative (mitotic) or meiotic phases of spermatogenesis. Spermiogenesis in rainbow trout has been characterized as a complex differentiation process (Billard, 1983). Abnormal spermatid development has been reported in triploid fowl (Lin et al., 1995a). Therefore, it is possible that, in spite of mechanistic difficulties for chromosomal disjunction, progression through meiosis could be accomplished in a triploid cell, while the unbalanced gene expression that presumably unfolds in the aneuploid spermatids present in triploid males is insufficient in most cases to accomplish the differentiation into spermatozoa satisfactorily.

Nevertheless, a few triploid individuals in the present study (one precocious male and three out of the ten males sampled at 25 months of age) produced morphologically normal spermatozoa. The appearance of normally differentiated spermatozoa may arise by chance from the random segregation of complete (haploid) chromosome sets. Alternatively, several cytological mechanisms capable of altering the chromosomal complement of triploid cells, such as multipolar mitosis, acytokinetic mitosis, cell fusion or chromosome elimination, may be operating in these males, as these have been described in other polyploids (Pera, 1975; Nakai et al., 1991; Ohtani, 1993). At present, the reasons for the individual variation detected in the effects of triploidy on testicular development remain unclear.

Early stages ( 7 months after fertilization) of spermatogenesis in triploid fish were also characterized by the presence of prominent Sertoli cells and a significant deficiency in interstitial (Leydig) cells. Sertoli cells are known to have phagocytic activity in teleosts (Billard, 1986). A possible explanation for the enlargement of Sertoli cells relates to the slight necrosis $(\mathrm{ARF}=0.69 \%)$ detected in triploid males, which was not observed in the diploid group at this age. Although the functional role of interstitial (Leydig) cells in teleosts is still subject to some discussion, these cells seem to participate in steroid biosynthesis, particularly of 11-ketotestosterone (de Vlaming, 1974; Grier, 1981; Nagahama, 1994). The observed scarcity of these cells in triploid males may explain the initially low concentrations of 11-ketotestosterone detected in maturing triploid male trout (Kobayashi et al., 1993).

Triploidy clearly affects ovarian development at an early stage, although in the present study the absence of sampling before 7 months of age prevented a clear identification of the time of impact. The main features noticed in the ovarian development of triploid female fish were the persistence of the oogonial nests, the gradual appearance of spermatogenic areas and the extreme proliferation of non-follicular elements in all females examined.

Most germ cells remained enclosed in the oogonial cysts throughout the 44 months covered in the sampling period, with only a few oocytes developing outside the cysts during the last sampling. In rainbow trout, as in other (but not all) salmonids and most vertebrate species, the germ cells are organized in clusters connected by intercellular bridges and surrounded by stromal cells (Takashima et al., 1980; van den Hurk and Slof, 1981; Nakamura and Nagahama, 1993). This organization arises during the mitotic proliferation of oogonia, in which cytokinesis is frequently incomplete. The germ cells in each cluster undergo synchronous meiotic progression up to the late pachytene stage, and it has been suggested that the intercellular bridges within the gonial clusters play an important role in synchronizing oocyte differentiation (Tokarz, 1978; Beers and Dekel, 1981). During early diplotene, the oocytes forming the clusters segregate and are gradually surrounded by somatic prefollicular cells (Peters, 1978). Primordial follicles formed in this way continue differentiation independently and asynchronously. The mechanisms leading to the disruption of the interoocyte bridges are still unclear, although it has been suggested that the thin cytoplasmic digitations that stromal cells develop around the clustered oocytes could play an active

Fig. 5. Gonadal photomicrograph from (a) a 7-month-old triploid female rainbow trout stained with haematoxylin-eosin (HE); (b) a 15-month-old triploid female stained with the periodic acid-Schiff reaction and counterstained with Heidenhain's iron haematoxylin (PAS-HIH); (c) a 20-month-old diploid female stained with Masson's trichromic stain; (d) a 20-month-old triploid female stained with HE; (e) a 20-month-old triploid female stained with HE; (f) a 20-month-old triploid female stained with PAS-HIH; (g) a 25-month-old triploid female stained with PAS-HIH; (h) a 25-month-old triploid female stained with $\mathrm{HE}$; (i,j) a 44-month-old triploid female stained with HE. A, adipocytes; AT, atretic oocyte; CO, cysted oogonia; FC, fibroblasts; FL, fibrous layer; G, granulosa; GE, germinal epithelium; GS, glandular structures; L, lamellae; $\mathrm{N}$, necrosis; O, oogonia; OL, ovarian lumen, $\mathrm{O} 3$, stage 3 oocyte; $\mathrm{O} 4$, stage 4 oocyte; $\mathrm{O} 6$, stage 6 oocyte; S, stroma; SC, spermatogenic cells; S1, primary spermatocytes; S2, secondary spermatocytes; ST, spermatids; T, theca; TA, tunica albuginea; VL, vascular lacunae; YG, yolk granules; YV, yolk vesicles; ZR, zona radiata. Scale bars represent $(a, c, f, j) 50 \mu \mathrm{m}$; (b, g) $25 \mu \mathrm{m}$; (d, e) $400 \mu \mathrm{m}$; and (h, i) $100 \mu \mathrm{m}$. 
mechanical role in this process (Andreuccetti et al., 1990). The presence of marginal numbers of oocytes developing outside the cysts to stages $4-5$ in the present study suggests that, rather than being due to the inability of the germ cells to progress through meiosis, the early blockage observed in triploid ovaries results from the sequestering of the oocytes within the gonial cysts. Furthermore, the observation of a normally developed granulosa around these extracystic oocytes suggests that, provided that the proper interactions with the developing oocytes can be established, granulosa cells in triploid females retain the potential to differentiate correctly.

Previous studies in salmonids have shown that the presence of a triploid genome results in an increase in cellular volume (Small and Benfey, 1987). Perhaps the alteration in cellular dimensions interferes with the intimate cell-to-cell communication required for the disruption of the oogonial clusters in triploid females, resulting in the persistence of the oogonial nests. Further studies on the ultrastructure of the granulosa and oocytes in diploid and triploid female teleosts will be of great value in clarifying the initial stages of the process of folliculogenesis in this species.

An alternative hypothesis considers that the lack of a proper hormonal environment prevents the disruption of the gonial cysts by inhibiting somatic-germ cell interactions, as has been hypothesized to occur during sex reversal in Xenopus (Villalpando and Merchant-Larios, 1990). Piferrer et al. (1994) detected no significant oocyte development in oestrogentreated triploid females of coho salmon. However, extrapolation of information obtained in this species to the rainbow trout may not be valid, since oogonia were not found to be arranged naturally in the cysts characteristic of normal ovarian development in rainbow trout, and the reproductive cycle of the coho salmon consists of a single spawn while the rainbow trout is a multiple spawner.

Oestradiol and testosterone implants significantly increase sGnRH contents in the brain and pituitary of adult triploid rainbow trout (Breton and Sambroni, 1996). Krisfalusi and Cloud (1996) observed no differences in the ovarian development of triploid rainbow trout treated with oestradiol by immersion of eyed eggs and alevins and oral administration, compared with untreated triploids. These findings suggest that the supplementation of exogenous steroids during early ontogeny is insufficient to overcome the blockage in oocyte development observed in triploid female trout, and that the significantly lower concentrations of gonadal steroids observed in female triploids (Lincoln and Scott, 1984; Nakamura et al., 1987) are a result of reduced ovarian development, rather than the cause. However, the supplementation of exogenous oestradiol may not be sufficient to restore the normal endocrine balance necessary for the initiation of folliculogenesis, which is likely to require both the establishment of the proper cellular interactions and the hormonal milieu necessary for the differentiation of the prefollicular cells and oogonia (Tokarz, 1978; Andreuccetti et al., 1990; Villalpando and Merchant-Larios, 1990; Moley and Schreiber, 1995).

An important feature of ovarian development in the triploid females in the present study was the gradual increase in frequency of male-differentiating areas observed between the second (three of the nine females examined; IRF $=0.8-6.8 \%$ ) and fifth samples (nine of the ten females examined, IRF $=1.8$
$38.6 \%$ ). The ovarian development of chromosomally female (3A: ZZW) triploid chickens follows a similar pattern. Most left gonads of ZZW triploid chickens appear as normal ovaries at hatching, but subsequently the gonad becomes an ovotestis as testicular tissue develops to produce abnormal spermatozoa by 25 weeks of age (Thorne et al., 1988; Fitzgerald and Cardona, 1993; Lin et al., 1995b). Testicular differentiation also occurs in mouse fetal ovaries after elimination of germ cells (Hashimoto et al., 1990). In mice, male somatic cells are autonomously committed to differentiate into Sertoli and peritubular (Leydig) cells, while specific somatic-germ cell interactions are required for the normal differentiation of female somatic cells (Burgoyne et al., 1988). In the absence of such interactions, female somatic cells differentiate into testis cords containing Sertoli and peritubular cells, but no other type of testis-specific cell (Hashimoto et al., 1990). Trout and chicken germ cells retain the potential to differentiate in the male or female direction, as shown by the readiness with which sex reversal can be induced in these species (Bye and Lincoln, 1986; Wartenberg et al., 1992). Thus, it seems possible that in triploid female trout, the persistence of the oogonial cysts precludes the establishment of the somatic-germ cell interactions necessary for female somatic cell differentiation. Female somatic cells may then differentiate into testis-supportive cells (Sertoli and Leydig cells), which could, in turn, favour the masculine differentiation of pluripotential germ cells in rainbow trout as well as in chickens. In the absence of further information (for example, ultrastructural studies on the ovarian development of triploid rainbow trout) this hypothesis remains mainly speculative.

Finally, the extreme proliferation of non-follicular components observed in triploid females is difficult to interpret, not only because of the diversity of the structures observed (that is, vascular lacunae, fibrous conglomerates and tubular proliferations) but also in view of the current scarcity of information on their origin and function in the vertebrate ovary. For instance, the significant enlargement of the germinal epithelium detected in triploid females in three of the samples performed is difficult to explain since, although it seemed to be closely associated with the development of satellite or follicle cells for adjacent germ cells, the functional role of the germinal epithelium remains unclear (Duke, 1978). Wilcox and Mossman (1945) claimed that testis-like cords observed in the ovaries of the vagrant shrew, Sorex vagrans, originated in the germinal epithelium. Price (1953) described the thickening of the germinal epithelium in the anoestrous water shrew, although no significance was attributed to this seasonal activity. Tumour-like cell masses resembling tubular adenomas have been described in the ovarian development of triploid ( $3 \mathrm{~A}: \mathrm{ZZW}$ ) intersex chickens (Frankenhuis, 1988) as well as in mouse ovaries deficient in germ cells (Duncan and Chada, 1993). The presence of extensive myeloid centres has been recorded in the ovary of elasmobranchs, in which haematopoietic elements from the kidney replace the original medullary tissue and persist there (Matthews, 1950; Franchi, 1962). Leukocytes infiltrate the gonads of triploid ZZW fowl (Lin et al., 1995b). The observation of inflammatory cells, fibrosis and necrosis would suggest the presence of some type of immune response during the ovarian development of triploid females, which may be related to the appearance of the proliferative structures mentioned. 
Overall, it seems that non-follicular components undergo abnormal differentiation, reflecting a certain degree of pluripotentiality in the triploid females examined. For example, the glandular formations resembling kidney tubules may represent overgrown remnants of the rete ovarii, which originate in the tubular connection that develops between the mesonephros and the gonad during organogenesis. However, the rete ovarii is normally absent in teleosts, first appearing in the ovaries of vertebrates in the Amphibia (Duke, 1978). Although it has been suggested that the rete system interacts with the ovarian cortex initiating the start of meiosis in mammals (Byskov, 1975), its ontogeny and functional role remain obscure.

The authors are indebted to R. Teplitz (University of California, Davis) for valuable discussion of the experimental design, and to J. Van Eeneenaam for technical expertise. L. Carrasco was supported in part by an MEC-Fulbright grant. This project was funded by European Union-DGXIV FAIR grant number GT952160 to L. Carrasco and N. Bromage.

\section{References}

Andreuccetti P, Motta CM and Filosa S (1990) Regulation of oocyte number during oocyte differentiation in the lizard (Podarcis sicula) Cell Differentiation and Development 29 129-141

Beers WH and Dekel N (1981) Intercellular communication and the control of oocyte maturation. In Dynamics of Ovarian Function pp 121-144 Eds NB Schwartz and M Hunzicker-Dunn. Raven Press, New York

Benfey TJ (1995) Ovarian development in triploid brook trout (Salvelinus fontinalis) Proceedings of the Fifth International Symposium on the Reproductive Physiology of Fish P 357 Eds FW Goetz and P Thomas. Austin, TX

Benfey TJ, Solar II, De Jong G and Donaldson EM (1986) Flow-cytometric confirmation of aneuploidy in sperm from triploid rainbow trout Transactions of the American Fisheries Society 115 838-840

Billard R (1983) Spermiogenesis in the rainbow trout (Salmo gairdneri) Cell and Tissue Research 233 265-284

Billard R (1986) Spermatogenesis and spermatology of some teleost fish species Reproduction, Nutrition, Développement 26 877-920

Billard R (1992) Reproduction in rainbow trout: sex differentiation, dynamics of gametogenesis, biology and preservation of gametes Aquaculture 100 263-298 In The Rainbow Trout Ed. GAE Gall. Elsevier Science, The Netherlands

Breton B and Sambroni E (1996) Steroid activation of the brain-pituitary complex gonadotropic function in the triploid rainbow trout (Oncorhynchus mykiss) General and Comparative Endocrinology 101 155-164

Bromage NR and Cumaranatunga R (1988) Egg production in the rainbow trout Recent Advances in Aquaculture 3 63-138

Burgoyne PS, Buehr M, Koopman P, Rossant J and MacLaren A (1988) Cellautonomous action of the testis-determining gene: Sertoli cells are exclusively $X Y$ in $X X \leftrightarrow X Y$ chimaeric mouse tests Development $102443-450$

Bye VJ and Lincoln RF (1986) Commercial methods for the control of sexual maturation in the rainbow trout (Salmo gairdneri R.) Aquaculture 57 299-309

Byskov AG (1975) The role of the rete ovarii in meiosis and follicle formation in the cat, mink and ferret Journal of Reproduction and Fertility 45 201-209

Carleton HM (1980) Carleton's Histological Techniques 5th Edn. Eds RAB Drury and EA Wallington. Oxford University Press, Oxford

Cerisola H and Dazarola G (1996) Morfología gonadal de trucha arcoiris Oncorhynchus mykiss tratada para la producción de monosexo y triploidia Archivos de Medicina Veterinaria 28 81-86 (in Spanish)

de Vlaming VL (1974) Environmental and endocrine control of teleost reproduction. In Control of Sex in Fishes pp 13-83 Ed. CB Schreck. Virginia Polytechnic Institute and State University, Blacksburg, VA

Devlin RH, Yesaki TY, Biagi CA, Swanson P, Chan WK and Donaldson EM (1994) Extraordinary salmon growth Nature 371 209-210

Duke KL (1978) Non-follicular ovarian components. In The Vertebrate Ovary pp 563-582 Ed. RE Jones. Plenum Press, New York and London

Duncan MK and Chada KK (1993) Incidence of tubulostromal adenoma of the ovary in aged germ cell-deficient mice Journal of Comparative Pathology 109 $13-19$
Fitzgerald SD and Cardona CJ (1993) True hermaphrodites in a flock of cochin bantams Avian Diseases $37912-916$

Franchi LL (1962) The structure of the ovary B: vertebrates. In The Ovary pp 121-143 Ed. S Zuckerman. Academic Press, New York

Frankenhuis MT (1988) Triploidy and intersexuality in adult layers Proceedings of the 18th World Poultry Congress pp 527-528 World's Poultry Science Association, Nagoya

Galbreath PF and Thorgaard GH (1995) Saltwater performance of all-female triploid Atlantic salmon Aquaculture 138 77-85

Grier HJ (1981) Cellular organization of the testis and spermatogenesis in fishes American Zoology 21 345-357

Hashimoto N, Kubokawa R, Yamazaki K, Noguchi M and Kato Y (1990) Germ cell deficiency causes testis cord differentiation in reconstituted mouse fetal ovaries Journal of Experimental Zoology $25361-70$

Hussain MG (1996) Advances in chromosome engineering research in fish: review of methods, achievements and applications Asian Fisheries Science 9 $45-60$

Ihssen PE, McKay LR, McMillan I and Phillips RB (1990) Ploidy manipulation and gynogenesis in fishes Transactions of the American Fisheries Society 119 698-717

Ihssen PE, McKay LR and McMillan I (1991) Growth and survival of triploid rainbow trout Bulletin of the Aquaculture Association of Canada 3 13-15

Johnson OW, Dickhoff WW and Utter FM (1986) Comparative growth and development of diploid and triploid coho salmon (Oncorhynchus kisutch) Aquaculture 57 329-336

Johnstone R (1995) Experience with salmonid sex reversal and triploidisation technologies in the United Kingdom Bulletin of the Aquaculture Association of Canada 96-2 9-13

Kobayashi T, Sakai N, Fushiki S, Nagahama Y, Amano M and Aida K (1993) Testicular development and changes in the levels of reproductive hormones in triploid male rainbow trout Nippon Suisan Gakaishi 59 981-989

Krisfalusi M and Cloud JG (1996) Effects of exogenous estradiol-17 $\beta$ on early growth and gonadal development of diploid and triploid female rainbow trout (Oncorhynchus mykiss) Developmental Genetics 19 302-308

Lin M, Thorne MH, Martin IC, Sheldon BL and Jones RC (1995a) Electron microscopy of the seminiferous epithelium in the triploid ( $Z Z Z$ and $Z Z W$ ) fowl (Gallus domesticus) Journal of Anatomy $186563-576$

Lin M, Thorne MH, Martin IC, Sheldon BL and Jones RC (1995b) Development of the gonads in the triploid (ZZW and ZZZ) fowl, Gallus domesticus, and comparison with normal diploid males (ZW) Reproduction. Fertility and Development 7 1185-97

Lincoln RF and Scott AP (1984) Sexual maturation in triploid rainbow trout (Salmo gairdneri Richardson) Journal of Fish Biology 25 385-392

Matthews LH (1950) Reproduction in the basking shark (Cetorhinus maximus) Philosophical Transactions of the Royal Society of London Series B 234 247-316

Moley KH and Schreiber JR (1995) Ovarian follicular growth, ovulation and atresia. Endocrine, paracrine and autocrine regulation Advances in Experimental Medicine and Biology 377 103-119

Nagahama $Y$ (1994) Endocrine regulation of gametogenesis in fish International Journal of Developmental Biology 38 217-229

Nakai Y, Kubota S and Kohno S (1991) Chromatin diminution and chromosome elimination in four Japanese hagfish species Cytogenetics and Cell Genetics 56 196-198

Nakamura M and Nagahama Y (1993) Ultrastructural study on the differentiation and development of steroid-producing cells during ovarian differentiation in the amago salmon (Oncorhynchus rhodurus) Aquaculture 112 237-25I

Nakamura M, Nagahama Y, Iwahashi M and Kojima M (1987) Ovarian structure and plasma steroid hormones of triploid female rainbow trout Nippon Suisan Gakaishi 531105

Ohtani H (1993) Mechanism of chromosome elimination in the hybridogenetic spermatogenesis of allotriploid males between Japanese and European waterfrogs Chromosoma 102 158-162

Okada H (1985) Studies on the Artificial Sex Control in Rainbow Trout (Salmo gairdneri) Canadian Translations of Fisheries and Aquatic Sciences Monograph 5329

Pera F (1975) Arrangement of spindle apparatus in mitoses of different ploidy Experimental Cell Research 92 419-427

Peters $\mathrm{H}$ (1978) Folliculogenesis in mammals. In The Vertebrate Ovary pp 121-I44 Ed. RE Jones. Plenum Press, New York and London

Piferrer F, Benfey TJ and Donaldson EM (1994) Gonadal morphology of normal and sex-reversed triploid and gynogenetic diploid coho salmon (Oncorhynchus kisutch) Journal of Fish Biology 45 541-553 
Price $M$ (1953) The reproductive cycle of the water shrew (Neomys fodiens) Proceedings of the Zoological Society of London $123599-621$

Small SA and Benfey TJ (1987) Cell size in triploid salmon Journal of Experimental Zoology 241 339-342

Sokal RR and Rohlf $\mathbf{J}$ (1981) Biometry 2nd Edn. WH Freeman and Co., New York

Takashima F, Patiño R and Nomura M (1980) Histological studies on the sex differentiation in rainbow trout Bulletin of the Japanese Society of Scientific Fisheries 46 1317-1322

Thorgaard GH (1986) Ploidy manipulation and performance Aquaculture 57 $57-64$

Thorgaard GH (1991) Integration of chromosome set manipulation and transgenic technologies for fishes Proceedings of the Second International Marine Biotechnology Conference p 63 Ed. WC Brown, Baltimore, MD

Thorne MH, Collins RK, Sheldon BL and Bobr LW (1988) Morphology of the gonads and reproductive ducts of triploid chickens Proceedings of the 18th World Poultry Congress pp 525-526 World's Poultry Science Association, Nagoya
Tokarz RR (1978) Oogonial proliferation, oogenesis and folliculogenesis in nonmammalian vertebrates. In The Vertebrate Ovary pp 145-179 Ed. RE Jones. Plenum Press, New York and London

van den Hurk R and Slof GA (1981) A morphological and experimental study of gonadal sex differentiation in the rainbow trout (Salmo gairdneri) Cell and Tissue Research 218 487-497

Villalpando I and Merchant-Larios H (1990) Determination of the sensitive stages for gonadal sex-reversal in Xenopus laevis tadpoles International journal of Developmental Biology 34 282-285

Wartenberg H, Lenz E and Schweikert HU (1992) Sexual differentiation and the germ cells in sex reversed gonads after aromatase inhibition in the chicken embryo Andrologia 24 1-6

Wattendorf RJ (1986) Rapid identification of triploid grass carp with a Coulter Counter and channelyzer Progressive Fish Culturist 48 125-132

Wilcox DE and Mossman HW (1945) The common occurrence of 'testis' cords in the ovaries of a shrew (Sorex vagrans) Anatomical Record 92 183-195 